\title{
Second-line pazopanib in patients with relapsed and refractory small-cell lung cancer: a multicentre phase II study of the Hellenic Oncology Research Group
}

F Koinis ${ }^{1}$, S Agelaki ${ }^{1}$, V Karavassilis ${ }^{1}$, N Kentepozidis ${ }^{1}$, E Samantas ${ }^{1}$, S Peroukidis ${ }^{1}$, P Katsaounis ${ }^{1}$, E Hartabilas ${ }^{1}$, I I Varthalitis ${ }^{1}$, I Messaritakis ${ }^{1}$, G Fountzilas ${ }^{1}$, V Georgoulias ${ }^{1}$ and A Kotsakis ${ }^{*}, 1,2$

${ }^{1}$ Hellenic Oncology Research Group (HORG), 55, Lombardou Street, Athens 11474, Greece

Background: Pazopanib is a tyrosine kinase inhibitor with antiangiogenic activity. Vascular endothelial growth factor expression is increased in SCLC and is correlated with poor prognosis. The efficacy and tolerance of second-line pazopanib in SCLC was evaluated.

Patients and methods: Patients with platinum-sensitive (cohort $A ; n=39$ ) and -resistant/refractory (cohort $B ; n=19$ ) SCLC were enrolled in a multicentre phase II study. The primary end point was the progression-free survival rate (PFS-R) at week 8 in each cohort. Pazopanib ( $800 \mathrm{mg}$ per day per os) was administered until progressive disease (PD). Circulating tumour cells (CTCs) were enumerated using the Cellsearch assay.

Results: All patients were evaluable for response and toxicity. In the intention-to-treat analysis, eight (13.8\%) patients achieved partial response (PR) (95\% confidence interval (CI): 5.0-22.7), 20 (34.5\%) stable disease (SD) and 30 (51.7\%) PD. Accrual in cohort B was halted because the hard-stop rule was met; in cohort A, the PFS-R was 59\% (95\% Cl: 43.5-74.4; PR=7, SD =16). Nine (23.1\%) patients received pazopanib for $>6$ months and 3 of them for $>12$ months. One pazopanib cycle resulted to a significant decrease to the number of patients with $\geqslant 5 \mathrm{CTCs} / 7.5 \mathrm{ml}$ of blood (20\%) compared with baseline (50\%). The median PFS and OS for all patients was 2.5 months (95\% Cl: 1.9-3.1 months) and 6.0 months ( $95 \% \mathrm{Cl}: 3.8-8.2$ months), respectively (cohort A: PFS $=3.7$ months and $\mathrm{OS}=8.0$ months). No unexpected toxicity was observed.

Conclusions: Second-line treatment with pazopanib in platinum-sensitive SCLC is well tolerated and resulted in promising objective responses and disease control; CTC enumeration might serve as a reliable surrogate biomarker of response.

Lung cancer is among the most frequently diagnosed cancer types and the leading cause of cancer-related deaths, worldwide (Jemal et al, 2011). Small-cell lung cancer (SCLC) accounts for $10 \%$ of the total number of lung cancers and represents an aggressive malignancy with a distinct natural history characterised by early dissemination and rapid doubling time (Travis et al, 1995;

\footnotetext{
*Correspondence: Professor A Kotsakis; E-mail: kotsakis@uoc.gr

Presented as an oral presentation at the 15th World Conference on Lung Cancer, 27-30 October 2013, Sydney, Australia; as a mini oral presentation at the 16th World Conference on Lung Cancer, 6-9 September 2015, Denver, CO, USA and as a poster presentation at the ASCO, 3-7 June 2016, Chicago, IL, USA.

${ }^{2}$ Current address: Department of Medical Oncology, University General Hospital of Heraklion, Heraklion, Greece.
}

Received 25 October 2016; revised 19 April 2017; accepted 24 April 2017; published online 16 May 2017

(C) 2017 Cancer Research UK. All rights reserved 0007-0920/17 
Gustafsson et al, 2008). The current standard of care for the management of extensive-stage SCLC (ED-SCLC) includes 4-6 chemotherapy cycles with a platinum agent and etoposide. Despite the efficacy of standard front-line regimens, the majority of ED patients relapse within 3-4 months, leading to a median survival of 8-13 months (van Meerbeeck et al, 2011). The dismal prognosis of SCLC patients, with a 5-year survival rate of $7 \%$, relies mainly on the limited options for the management of relapsed patients. Indeed, during the past 30 years, topotecan is the only approved drug for the second-line setting (O'Brien et al, 2006) and the various efforts for new treatments were without success (Jalal et al, 2009; Pallis et al, 2009; Ciuleanu et al, 2010; Satouchi et al, 2014; von Pawel et al, 2014; Koinis et al, 2016).

Angiogenesis is one of the hallmarks of malignant diseases contributing to tumour progression and metastasis (Hanahan and Weinberg, 2011). Angiogenesis is of paramount importance in SCLC based on the high microvessel density and VEGF expression in almost $80 \%$ of SCLC cases (Lucchi et al, 2002; Dowell et al, 2004). In addition, high levels of serum VEGF or VEGF overexpression in tumour samples have been associated with poor response to chemotherapy and inferior survival (Salven et al, 1998; Tas et al, 2006; Ustuner et al, 2008; Zhan et al, 2009). Pazopanib (Votrient; Novartis, Fabrikstrasse, Basel, Switzerland) is a potent, competitive inhibitor of the tyrosine kinase activity (TKI) of VEGF receptors (VEGFR-1, -2 and -3), platelet-derived growth factor receptor (PDGFR) and c-kit, capable of inhibiting downstream signalling from these receptors (Kumar et al, 2007). It has been already approved for the treatment of renal cell carcinoma (Sternberg et al, 2010) and soft-tissue sarcomas (van der Graaf et al, 2012). As there is an unmet need for the development of new active therapeutic options for relapsed SCLC patients, the Lung Cancer Working Group of the Hellenic Oncology Research Group (HORG) conducted a multicentre, single-arm, phase II study of pazopanib as second-line treatment in patients with both platinum-resistant/refractory and platinum-sensitive SCLC.

\section{PATIENTS AND METHODS}

Key eligibility criteria. Patients with histologically or cytologically confirmed SCLC and radiologically documented progressive disease (PD) after first-line chemotherapy or chemoradiotherapy were recruited. Both patients with sensitive (relapse $>90$ days after completion of front-line therapy; cohort A) and refractory or resistant (unresponsive to initial therapy and relapse within 90 days following completion of initial treatment, respectively; cohort B) were enrolled. Additional eligibility criteria included age $\geqslant 18$ years, measurable disease according to RECIST v.1.1 (Eisenhauer et al, 2009), adequate liver, renal and bone marrow function, ability to swallow oral medications and an ECOG performance status of $\leqslant 2$. Patients with brain metastasis were enrolled provided that they were irradiated at least 4 weeks before the first administration of the study drug, and were neurologically stable. Patients with poorly controlled hypertension, corrected QT interval >480 ms (using Bazett's formula) or significant cardiac morbidity within the past 6 months were excluded. Additional exclusion criteria included a history of cerebrovascular accident, transient ischemic attack, pulmonary embolism or untreated deep venous thrombosis within the past 6 months, prior major surgery or trauma within 28 days before treatment initiation and/or presence of any nonhealing wound, fracture, ulcer, evidence of active bleeding or bleeding diathesis, haemoptysis, clinically significant gastrointestinal abnormalities that might increase the risk for bleeding and any serious and/or unstable pre-existing medical, psychiatric or other condition that could interfere with subject's safety, provision of informed consent or compliance to study procedures. The trial was approved by the institutional review board of the participating centres, as well as by the Hellenic Drug and Food Organisation (EOF) and the National Ethics Committee (EED); the study was conducted in accordance with the Declaration of Helsinki and Good Clinical Practice. All patients gave written informed consent.

Treatment and response assessments. Pazopanib was given at a dose of $800 \mathrm{mg}$ per day, orally, once daily. Toxicity was graded according to the Common Terminology Criteria for Adverse Events (NCI CTCAE v.4.03, National Cancer Institute, 2015). Tumour response assessment (by physical examination and CT scans) using the RECIST criteria v.1.1 (Eisenhauer et al, 2009) was performed every two cycles (each cycle of 28 days), or earlier if clinically indicated. The pazopanib dose was adjusted (by $200 \mathrm{mg}$ decrements or treatment interruptions) according to patients' tolerance. Treatment was discontinued in case of unacceptable toxicity, treatment delay $>2$ weeks due to insufficient recovery from toxicity or if more than two dose reductions were required. Patients continued treatment until disease progression, occurrence of unacceptable toxicity or consent withdrawal.

Detection of CTCs. Of the 58 patients who were treated with pazopanib in the context of this phase II study, 56 had evaluable baseline CTC measurement by CellSearch (CS) assay (Supplementary Figure 1). Peripheral blood $(7.5 \mathrm{ml}$ in CellSave Preservative Tubes; Veridex LLC, Raritan, NJ, USA) was obtained before the administration of the first pazopanib dose (baseline; $n=56$ ), before the initiation of the second cycle (post first cycle; $n=35$ ) and at the time of clinical or radiological disease progression (PD; $n=45$; Supplementary Figure 1). All blood samples were obtained at the middle of vein puncture after the first $5 \mathrm{ml}$ were discarded to avoid contamination with skin epithelial cells. Blood samples were processed within $72 \mathrm{~h}$. The CS (Veridex LCC) assay for the detection of CTCs was performed using the CellTracks Analyser II as reported previously (Allard et al, 2004) and according to the manufacturer's instructions. The detection of $5 \mathrm{CTCs} / 7.5 \mathrm{ml}$ of blood was considered as the cutoff to characterise a blood sample as positive according to the manufacturer's instructions.

End points and statistical considerations. This was a multicentre, open-label, non-randomised, single-arm phase II trial that enrolled patients in two parallel cohorts (cohorts A and B).

The primary end point of the study was the progression-free survival rate (PFS-R) at week 8 in both cohorts, as determined by radiological assessment using the standard RECIST criteria v.1.1. Progression-free survival rate (Van Glabbeke et al, 2002) was selected as the primary end point because the objective response rate (ORR) might not be the optimal tool to measure the efficacy of antiangiogenic treatment (Michaelis and Ratain, 2006).

The null hypothesis for both cohorts was that pazopanib is not active, whereas the alternative hypothesis was that it is active. These hypotheses are expressed as $\mathrm{H}_{\mathrm{o}}$ : PFS- $\mathrm{R} \leqslant 0.30$ vs $\mathrm{H}_{\mathrm{a}}$ : PFS- $\mathrm{R}$ $\geqslant 0.50$. The study hypotheses were based on results of intravenous topotecan monotherapy in relapsed SCLC in both sensitive and refractory patients (Ardizzoni, 2004).

The study followed a Simon's min-max two-stage design. Nineteen patients should be enrolled into each cohort during the first step of the study and if 7 or more subjects in cohort A or B did not experience PD at week 8, 20 additional patients would be enrolled in each cohort during the second step of the trial (a total of 39 patients per cohort). The null hypothesis would be rejected in favour of the alternative hypothesis if 17 or more patients among the 39 subjects in each cohort experience disease control at week 8 . The type I error rate with this design is 0.05 , the type II error is 0.2 and the power is $80 \%$. 
The secondary end points included the (i) PFS, measured from the date of enrolment until the date of PD or death, whichever is first reported; (ii) overall survival (OS), measured from the date of enrolment to the date of death from any reason; (iii) ORR according to the RECIST criteria; and (iv) toxicity profile.

An intention-to-treat (ITT) analysis was performed in both cohorts together as well as separately. The detection of positive CTCs was compared using the two-sided Fisher's exact test for categorical variables. Progression-free survival and OS for all patients were calculated using the Kaplan-Meier analysis and the comparisons were computed using the log-rank test. Ninety-five per cent confidence intervals $(95 \% \mathrm{CI})$ are also presented, as appropriate. All clinical data were held centrally (Clinical Trial Office, HORG) and analysed using the SPSS statistical software, version 22.0 (SPSS Inc., Chicago, IL, USA).

\section{RESULTS}

Patients' characteristics. Between October 2011 and September 2014, 58 patients were enrolled in cohorts A $(n=39)$ and B $(n=19)$. Recruitment in cohort B was terminated at the interim analysis owing to the lack of efficacy. Patients' characteristics are summarised in Table 1. Median age was 64.5 years (range, 39-82), $50(86.2 \%)$ patients were male and $55(94.8 \%)$ had an ECOG performance status of 0 or 1 . All patients received front-line chemotherapy with etoposide/cisplatin (or carboplatin), while concomitant chest radiotherapy was administered in 16 patients $(27.6 \%)$ with limited disease; six $(10.3 \%)$ patients had brain metastasis.

Drug exposure and toxicity. A total of 206 cycles were administered. Dose reduction was required in 18 cycles due to haematologic toxicity ( $n=2$ cycles), non-haematologic toxicity ( $n=14$ cycles) and both haematologic and non-haematologic toxicity ( $n=2$ cycles). The median dose intensity was $560 \mathrm{mg}$ per day per os corresponding to $70 \%$ of the protocol planned dose.

At the time of analysis, all patients had discontinued treatment because of disease progression ( $\mathrm{PD} ; n=43$ patients); in addition, 15 patients discontinued treatment for the following reasons: (i) consent withdrawn after the first cycle ( $n=4$ patients) as a result of personal decision (1 patient) and adverse events (AEs) $((n=3$ patients): grade 4 diarrhoea (1 patient); grade 4

\begin{tabular}{|c|c|c|}
\hline & $N=58$ & $\%$ \\
\hline $\begin{array}{l}\text { Age (years) } \\
\text { Median (min-max) }\end{array}$ & \multicolumn{2}{|c|}{64.5 (39-82) } \\
\hline $\begin{array}{l}\text { Sex } \\
\text { Male } \\
\text { Female }\end{array}$ & $\begin{array}{r}50 \\
8\end{array}$ & $\begin{array}{l}86.2 \\
13.8\end{array}$ \\
\hline $\begin{array}{l}\text { Performance status } \\
0 \\
1 \\
2\end{array}$ & $\begin{array}{r}31 \\
24 \\
3\end{array}$ & $\begin{array}{r}53.4 \\
41.4 \\
5.2\end{array}$ \\
\hline $\begin{array}{l}\text { Stage } \\
\text { Limited } \\
\text { Metastatic }\end{array}$ & $\begin{array}{l}15 \\
43\end{array}$ & $\begin{array}{l}25.9 \\
74.1\end{array}$ \\
\hline $\begin{array}{l}\text { Prior RT } \\
\text { RT lung - mediastinum } \\
\text { RT CNS } \\
\text { Both } \\
\text { Bones }\end{array}$ & $\begin{array}{r}30 \\
12 \\
13 \\
4 \\
1\end{array}$ & $\begin{array}{r}51.7 \\
20.7 \\
22.4 \\
6.9 \\
1.7\end{array}$ \\
\hline $\begin{array}{l}\text { Group } \\
\text { Platinum sensitive } \\
\text { Platinum resistant/refractory }\end{array}$ & $\begin{array}{l}39 \\
19\end{array}$ & $\begin{array}{l}67.2 \\
32.8\end{array}$ \\
\hline
\end{tabular}

transaminasaemia ( 1 patient) and grade 4 neutropenia ( 1 patient), (ii) physician's decision (2 patients), (iii) lost to follow-up (1 patient) and death not related to treatment (1 patient). Two patients were alive at the time of analysis. For 55 patients death was due to disease progression and one to cardiorespiratory failure; this death was deemed unrelated to study treatment.

All patients were evaluable for toxicity and the observed AEs are summarised in Table 2. The most frequent all-grade toxicities were anaemia and thrombocytopenia, which occurred in 26 (44.7\%) and $22(37.8 \%)$ patients, respectively. No grade 3-4 anaemia was observed, while grade 3 thrombocytopenia and grade 3-4 neutropenia occurred in one and two patients, respectively. Other common grade 3 or 4 AEs were transaminasaemia (8.6\%), fatigue (6.9\%) and diarrhoea (5.1\%). One patient experienced grade 3 hypertension. Thyroid function abnormalities were detected in three $(5.1 \%)$ patients, but all were grade 1 or 2 . There was no treatment-related death.

Effect of pazopanib on CTCs. The administration of one pazopanib cycle resulted in a significant decrease to the number of patients with $\geqslant 5 \mathrm{CTCs} / 7.5 \mathrm{ml}$ of blood $(20.0 \%)$ compared with baseline (50.0\%). Moreover, the number of CTCs was significantly decreased after one pazopanib cycle compared with baseline values (median number: 5 (range, 0-11 143 CTCs) and 0 (range, 0-804 CTCs) CTCs $/ 7.5 \mathrm{ml}$ of blood before and after one cycle of treatment, respectively $(P=0.043))$. At the time of $\mathrm{PD}, 18$

Table 2. Adverse events possibly or probably related to study treatment $(N=58)$

\begin{tabular}{|c|c|c|c|c|c|c|}
\hline & \multicolumn{2}{|c|}{ All grades } & \multicolumn{2}{|c|}{ Grade III } & \multicolumn{2}{|c|}{ Grade IV } \\
\hline & $N$ & $\%$ & $N$ & $\%$ & $N$ & $\%$ \\
\hline Leukopenia & 20 & 34.4 & 1 & 1.7 & 1 & 1.7 \\
\hline Neutropenia & 12 & 20.6 & 1 & 1.7 & 1 & 1.7 \\
\hline Febrile neutropenia & - & - & - & - & - & - \\
\hline Anaemia & 26 & 44.7 & - & - & - & - \\
\hline Thrombocytopenia & 22 & 37.8 & 1 & 1.7 & - & - \\
\hline Nausea & 11 & 18.9 & 1 & 1.7 & - & - \\
\hline Vomiting & 5 & 8.6 & - & - & - & - \\
\hline Diarrhoea & 13 & 22.4 & 2 & 3.4 & 1 & 1.7 \\
\hline Mucositis & 4 & 6.9 & - & - & - & - \\
\hline Constipation & 6 & 10.3 & - & - & - & - \\
\hline Neurotoxicity & 3 & 5.2 & - & - & - & - \\
\hline Rash & 3 & 5.2 & - & - & - & - \\
\hline Skin toxicity & 2 & 3.4 & - & - & - & - \\
\hline Infection & 3 & 5.2 & - & - & - & - \\
\hline Fatigue & 26 & 44.7 & 4 & 6.9 & - & - \\
\hline Transaminase elevations & 6 & 10.3 & 4 & 6.9 & 1 & 1.7 \\
\hline Hypercholesterolaemia & 2 & 3.4 & - & - & - & - \\
\hline Hypertension & 2 & 3.4 & 1 & 1.7 & - & - \\
\hline Ocular disturbance & 2 & 3.4 & - & - & - & - \\
\hline Hair discolouration & 4 & 6.9 & - & - & 1 & 1.7 \\
\hline Epistaxis & 1 & 1.7 & - & - & - & - \\
\hline Cardiotoxicity & 1 & 1.7 & - & - & - & - \\
\hline LDH elevation & 2 & 3.4 & - & - & - & - \\
\hline$\gamma$ GT elevation & 2 & 3.4 & - & - & - & - \\
\hline Proteinuria & 3 & 5.2 & - & - & - & - \\
\hline Thyroid dysfunction & 3 & 5.2 & - & - & - & - \\
\hline Hand foot syndrome & 2 & 3.4 & 1 & 1.7 & - & - \\
\hline
\end{tabular}


(40.0\%) out of 45 evaluable patients had an increased number of CTCs (median number 2 CTCs $/ 7.5 \mathrm{ml}$ of blood; range, 0-16 806 CTCs) compared with the number of CTC-positive patients after the first pazopanib cycle $(P=0.027)$.

Efficacy. All patients were evaluable for response. The objective responses were confirmed by an independent radiologist. In the ITT analysis of all 58 enrolled patients, a partial response (PR) was documented in eight patients (13.8\%; 95\% CI: 5.0-22.7), stable disease (SD) in 20 (34.5\%) and PD in 30 (51.7\%). The interim analysis of patients enrolled in cohort B indicated that one patient experienced PR for an ORR of 5.3\% (95\% CI: 0-15.3) and four achieved SD lasting for $>8$ weeks (PFS-R: 26.3\%; 95\% CI: 6.52-46.12); since the hard-stop rule was achieved in cohort B, further accrual was halted. On the contrary, the interim analysis in cohort A revealed that more than seven patients experienced disease control at week 8 and enrollment was continued according to the study design. In group A patients, the PFS-R was $59 \%$ ( $n=23$ patients; 95\% CI: 43.5-74.4\%); PR was achieved in seven patients (17.9\%; 95\% CI: 5.9-30) and SD in 16 (41\%); there was no patient with CR.

In the whole group of patients, the median PFS and OS were 2.5 months (range, 0.1-2.04 months; 95\% CI: 1.9-3.1 months) and 6.0 months (range, 0.5-38.4 months; 95\% CI: 3.8-8.2 months), respectively. Nine (15.5\%) patients received the study drug for $>6$ months (range, 6-24,3 months) and 3 of them for $>12$ months (one for 24.3 months, one for 19.7 months and a third for 12 months). The median PFS in cohorts A and B was 3.7 months (range, 0.1-23 months) and 2 months (range, 0.3-6 months), respectively (Figure 1A). Similarly, the median OS for the patients in cohorts $\mathrm{A}$ and $\mathrm{B}$ was 8.0 months (range, 1-38.4 months) and 4 months (range, 0.5-15.7 months), respectively, with a 1-year survival rate of $26.5 \%$ (cohort A) and $10.5 \%$ (cohort B; Figure $1 \mathrm{~B}$ ). In addition, patients with $\geqslant 5 \mathrm{CTCs} / 7.5 \mathrm{ml}$ at baseline had significantly shorter PFS (1.9 months, 95\% CI: 0.9-2.8 vs 3.6 months, 95\% CI: 1.3-5.9; $P<0.001$, Figure 2A) and OS (5.2 months, 95\% CI: 2.4-7.9 vs 10.1 months 7.4-12.8; $P=0.001$, Figure 2B).

Correlation of CTC changes and response to treatment. Further analysis of the CTC number revealed a significant correlation between their number and the treatment efficacy. Patients with disease control $(\mathrm{PR}+\mathrm{SD})$ had a significantly lower number of

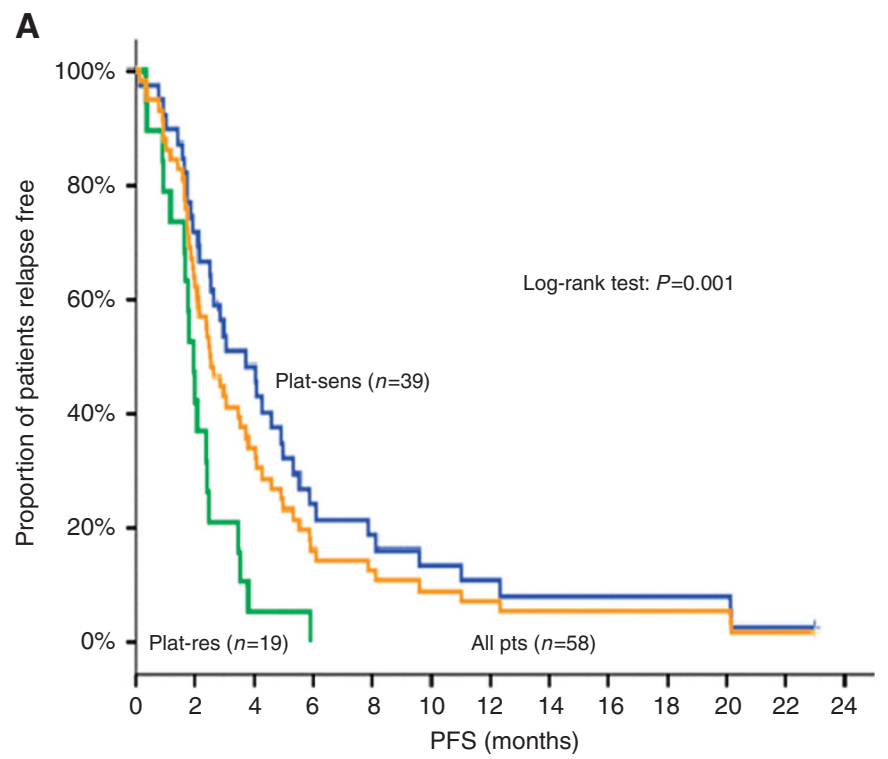

CTCs compared to patients with PD at all evaluated time points (baseline, after one pazopanib cycle and on $\mathrm{PD} \quad(P<0.001$; $P=0.016$ and $P=0.05$, respectively; Supplementary Table 1 and Supplementary Figure 2). Further analysis of paired samples revealed that patients with a high number of CTCs ( $\geqslant 5$ CTCs/ $7.5 \mathrm{ml}$ of blood) both at baseline and after one pazopanib cycle had a significantly shorter OS compared to patients with a low CTC number $(<5 \mathrm{CTCs} / 7.5 \mathrm{ml})$ at both time points. Similarly, the median OS was significantly higher in patients without detectable CTCs after one pazopanib cycle compared to patients with detectable CTCs $(P=0.036)$ as well as in patients with a low number of CTCs at baseline and a high number of CTCs $(\geqslant 5$ CTCs/7.5 ml) after one treatment cycle (Supplementary Figure 3).

\section{DISCUSSION}

Over the past decades no significant advances in the management of SCLC patients have been achieved. However, recent studies have shed light on the molecular biology of this tumour and new treatment targets have emerged and a shift towards molecular targeted approaches has been arisen. Although various agents have already been tested in different settings in SCLC, none of them has gained approval from the regulatory authorities, thus far (Koinis et al, 2016).

In the current multicentre, phase II study, the efficacy and toxicity of single-agent pazopanib, as second-line treatment in patients with SCLC, was investigated. The primary end point was met in patients with platinum-sensitive disease. For this group of patients, the PFS-R was 59\%, the ORR 17.9\%, the PFS 3.7 months and the OS 8 months. A systematic analysis of 21 clinical trials investigating different second-line chemotherapeutic regimens in SCLC, the ORR and the OS for patients with sensitive disease were $27 \%$ and 7.7 months, respectively (Owonikoko et al, 2012), whereas second-line chemotherapy in these patients resulted in a PFS of $\sim 3$ months and an OS of 6-8 months (von Pawel et al, 1999, 2001; Eckardt et al, 2007). Conversely, in patients with refractory disease the corresponding efficacy end points were lower, as expected, since these patients have a negligible chance to respond to any systemic second-line monotherapy (Owonikoko et al, 2012).

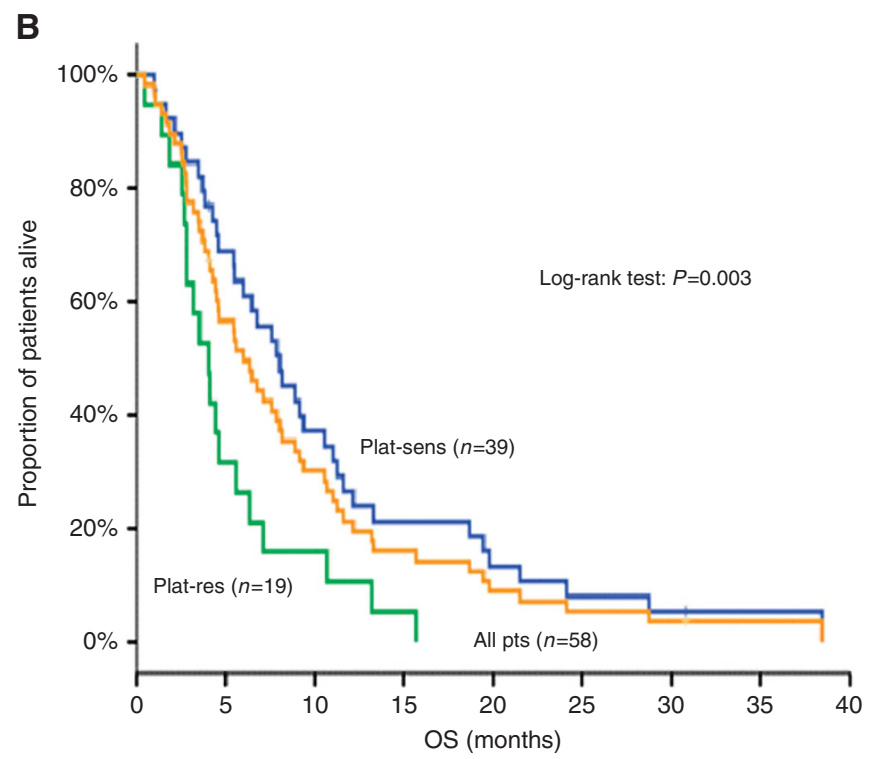

Figure 1. Survival curves of SCLC patients receiving pazopanib according to disease status. Kaplan-Meier curves for PFS (A) and OS (B) according to the platinum sensitivity. 

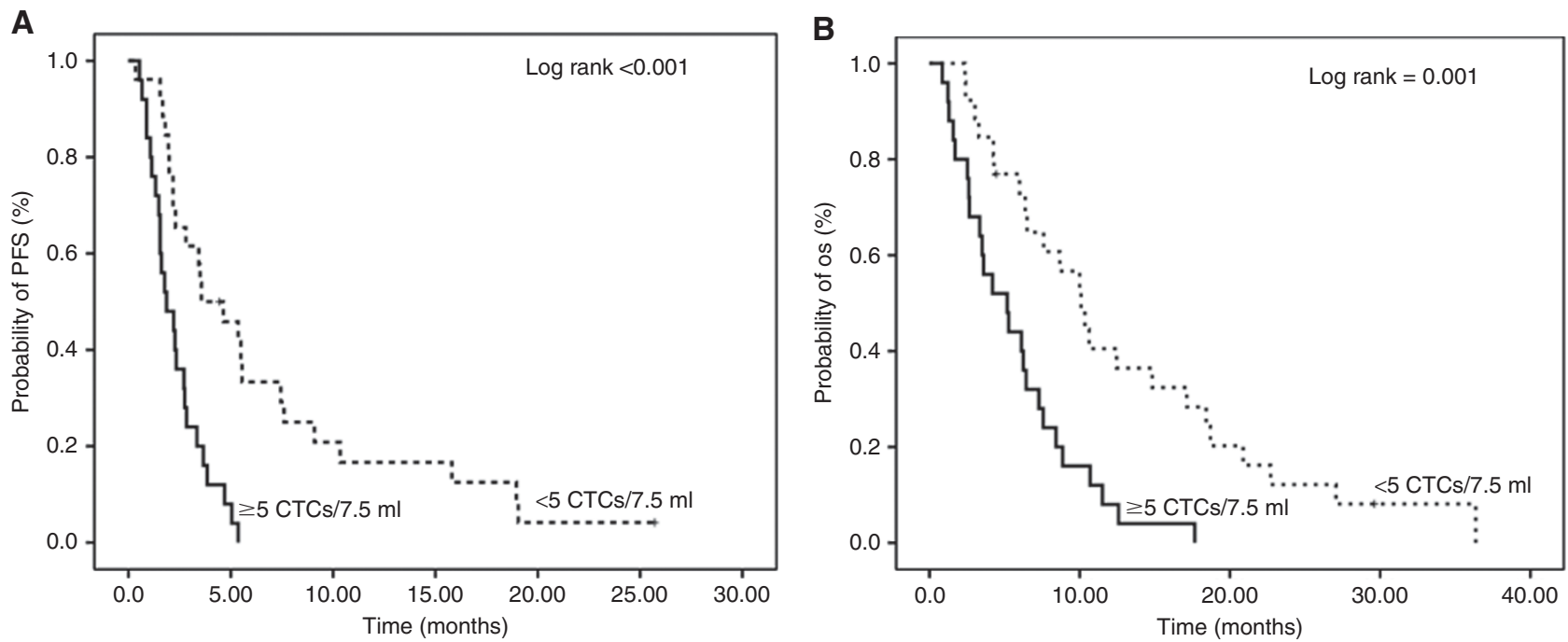

Figure 2. Survival curves of SCLC patients receiving pazopanib according to baseline levels of CTC's. Kaplan-Meier curves for PFS (A) and OS (B) according to the number of CTCs $/ 7.5 \mathrm{ml}$ of blood at baseline.

To the best of our knowledge, this is the first study reporting that an antiangiogenic TKI demonstrates a substantial and clinically relevant efficacy, as salvage treatment in patients with platinum-sensitive SCLC. Considering that antiangiogenic agents might have antitumour efficacy even in the absence of a robust RECIST-based response, the eight objective responses seen in our trial serve as evidence of therapeutic activity of VEGF tyrosine kinase inhibition in platinum-sensitive SCLC patients. This hypothesis is further supported by the fact that nine (15.5\%) patients received the study treatment for more than 6 months and 3 of them for more than 12 months. Moreover, it is interesting to note that pazopanib administration was associated with a significantly lower incidence of CTC-positive patients. The effect of pazopanib on CTCs was an early phenomenon, as it was observed after the administration of only one cycle; conversely, the number of CTCs was significantly increased at the time of clinical relapse compared with their number post first cycle. Moreover, it is interesting that the number of CTCs was significantly correlated with the treatment efficacy since patients with a low number of CTCs either before treatment or after one treatment cycle had a significantly higher probability to respond to treatment. In addition, the presence of a high CTC number both at baseline and after one pazopanib cycle was significantly correlated with shorter OS (Figure 2 and Supplementary Figure 3). In a preliminary correlative study, we observed that CTCs express the VEGFR2 and the number of VEGFR2-positive CTCs is significantly decreased after one pazopanib cycle (data not shown); this observation could explain, at least partially, the effect of pazopanib on CTCs. These findings strongly suggest that monitoring CTC changes during pazopanib administration could represent a dynamic biomarker in patients treated with an antiangiogenic agent, and, thus, it is reasonable to hypothesise that measurement of CTCs in SCLC patients deserves further evaluation as an efficacy surrogate biomarker.

Several clinical trials have investigated the efficacy of antiangiogenic therapies in SCLC. However, the results from most of these studies were disheartening. A single-arm, phase II study of second-line bevacizumab/paclitaxel in patients with a sensitive relapse yielded a median PFS of 14.7 weeks and an ORR of $18.1 \%$ (Jalal et al, 2010), whereas in a study with the same regimen in patients with chemoresistant disease, the ORR was $20 \%$ with a median PFS and OS of 2.7 and 6.3 months, respectively (Mountzios et al, 2012). Similarly, TKIs targeting the VEGFR have been explored in the second-line setting in SCLC. Treatment with the multikinase inhibitor sorafenib resulted in an ORR of $11 \%$ with a median OS of 6.7 months in the subgroup of platinumsensitive patients (Gitlitz et al, 2010). Cediranib, a VEGFR-1, -2 and -3 TKI, was evaluated in a phase II trial that was prematurely terminated owing to the lack of efficacy at the interim analysis (Ramalingam et al, 2010). Moreover, vandetanib, a multikinase inhibitor including VEGFR, failed as a maintenance treatment in SCLC patients achieving a response to first-line chemotherapy (Arnold et al, 2007). However, a phase II, randomised placebocontrolled trial of sunitinib as maintenance treatment improved PFS compared with placebo (median PFS 3.7 months for sunitinib and 2.1 months for placebo) after standard first-line chemotherapy in patients with extensive SCLC (Ready et al, 2015). However, the patients' tolerance to treatment was very poor, as the rate of grade $\geqslant 3$ AEs was $53.5 \%$ on sunitinib. In contrast, in the current study pazopanib demonstrated an acceptable and easily manageable toxicity profile. In fact, the toxicity profile noted in the current study is similar to that reported in previous studies with pazopanib in renal cell carcinoma, with elevated aminotransferases being the most prevalent grade 3-4 AE (Motzer et al, 2013; Escudier et al, 2014). It is to note that a treatment associated with a prolongation of PFS and with minimal toxicity compared with other options for relapsed patients with platinum-sensitive SCLC, should be considered as clinically relevant. Although quality of life issues were not assessed in a comprehensive manner in our study, representing a limitation of the trial, pazopanib improved the disease-related symptoms in the group of patients who experienced long-lasting disease control for more than 6 months.

As far as the other tyrosine kinase receptors that are also targeted by pazopanib are concerned, both c-kit (Rygaard et al, 1993) and PDGFR (Shinohara et al, 2007) are expressed in SCLC tumours. Although c-kit expression has been suggested as a prognostic factor (Micke et al, 2003), clinical studies investigating c-kit inhibition, clearly, did not demonstrate sufficient efficacy in terms of ORR or survival and its further development stopped (Johnson et al, 2003; Dy et al, 2005; Krug et al, 2005). On the other hand, PDGFR expression has not been shown to hold any prognostic or predictive value in SCLC (Shinohara et al, 2007) and therefore targeting PDGFR pathway is not considered clinically meaningful in SCLC.

In conclusion, pazopanib showed a promising activity as second-line treatment in patients with platinum-sensitive SCLC. Based on these findings, further evaluation of this drug is justified, in relapsed SCLC patients with sensitive disease, alone, in 
combination with other agents or as maintenance treatment in patients responding to front-line treatment. Finally, the monitoring of CTCs could contribute to the early detection (after one treatment cycle) of the patients who most likely will benefit from pazopanib and might serve as an early reliable surrogate biomarker that predict for response according to radiographic criteria.

\section{ACKNOWLEDGEMENTS}

We thank Dora Hatzidaki, Eva Maragoudaki, Ioannis Athanasakis, Marina Mavrogianni, Vassiliki Schoina, Aspasia Dimou, Spiros Georgiadis, Ageliki Kalisperi and Efthimios Prinarakis for their contribution to this research. We also thank the scientific secretary Vasso Athanasaki for her attentive editing of this manuscript. This work was supported by an unrestricted research grant from Novartis (CT/11.01 - 21/7/2011) and the Cretan Association for Biomedical Research (CABR).

\section{CONFLICT OF INTEREST}

The authors declare no conflict of interest.

\section{REFERENCES}

Allard WJ, Matera J, Miller MC, Repollet M, Connelly MC, Rao C, Tibbe AG, Uhr JW, Terstappen LW (2004) Tumor cells circulate in the peripheral blood of all major carcinomas but not in healthy subjects or patients with nonmalignant diseases. Clin Cancer Res 10(20): 6897-6904.

Ardizzoni A (2004) Topotecan in the treatment of recurrent small cell lung cancer: an update. Oncologist 9(Suppl 6): 4-13.

Arnold AM, Seymour L, Smylie M, Ding K, Ung Y, Findlay B, Lee CW, Djurfeldt M, Whitehead M, Ellis P, Goss G, Chan A, Meharchand J, Alam Y, Gregg R, Butts C, Langmuir P, Shepherd F (2007) Phase II study of vandetanib or placebo in small-cell lung cancer patients after complete or partial response to induction chemotherapy with or without radiation therapy: National Cancer Institute of Canada Clinical Trials Group Study BR.20. J Clin Oncol 25(27): 4278-4284.

Ciuleanu T, Samarzjia M, Demidchik Y, Beliakouski V, Rancic M, Bentsion L, Orlov V, Schaeffler A, De Jager L, Breitz B (2010) Randomized phase III study (SPEAR) of picoplatin plus best supportive care (BSC) or BSC alone in patients (pts) with SCLC refractory or progressive within 6 months after first-line platinum-based chemotherapy. Presented at the 2010 ASCO Annual Meeting 28: Suppl 15 (abstract 7002).

Dowell JE, Amirkhan RH, Lai WS, Frawley WH, Minna JD (2004) Survival in small cell lung cancer is independent of tumor expression of VEGF and COX-2. Anticancer Res 24(4): 2367-2373.

Dy GK, Miller AA, Mandrekar SJ, Aubry MC, Langdon Jr RM, Morton RF, Schild SE, Jett JR, Adjei AA (2005) A phase II trial of imatinib (ST1571) in patients with c-kit expressing relapsed small-cell lung cancer: a CALGB and NCCTG study. Ann Oncol 16(11): 1811-1816.

Eckardt JR, von Pawel J, Pujol JL, Papai Z, Quoix E, Ardizzoni A, Poulin R, Preston AJ, Dane G, Ross G (2007) Phase III study of oral compared with intravenous topotecan as second-line therapy in small-cell lung cancer. J Clin Oncol 25(15): 2086-2092.

Eisenhauer EA, Therasse P, Bogaerts J, Schwartz LH, Sargent D, Ford R, Dancey J, Arbuck S, Gwyther S, Mooney M, Rubinstein L, Shankar L, Dodd L, Kaplan R, Lacombe D, Verweij J (2009) New response evaluation criteria in solid tumours: revised RECIST guideline (version 1.1). Eur J Cancer 45(2): 228-247.

Escudier B, Porta C, Bono P, Powles T, Eisen T, Sternberg CN, Gschwend JE, De Giorgi U, Parikh O, Hawkins R, Sevin E, Negrier S, Khan S, Diaz J, Redhu S, Mehmud F, Cella D (2014) Randomized, controlled, doubleblind, cross-over trial assessing treatment preference for pazopanib versus sunitinib in patients with metastatic renal cell carcinoma: PISCES Study. J Clin Oncol 32(14): 1412-1418.
Gitlitz BJ, Moon J, Glisson BS, Reimers HJ, Bury MJ, Floyd JD, Schulz TK, Sundaram PK, Ho C, Gandara DR (2010) Sorafenib in platinum-treated patients with extensive stage small cell lung cancer: a Southwest Oncology Group (SWOG 0435) phase II trial. J Thorac Oncol 5(11): 1835-1840.

Gustafsson BI, Kidd M, Chan A, Malfertheiner MV, Modlin IM (2008) Bronchopulmonary neuroendocrine tumors. Cancer 113(1): 5-21.

Hanahan D, Weinberg RA (2011) Hallmarks of cancer: the next generation. Cell 144(5): 646-674.

Jalal S, Ansari R, Govindan R, Bhatia S, Bruetman D, Fisher W, Masters G, White A, Stover D, Yu M, Hanna N (2009) Pemetrexed in second line and beyond small cell lung cancer: a Hoosier Oncology Group phase II study. J Thorac Oncol 4(1): 93-96.

Jalal S, Bedano P, Einhorn L, Bhatia S, Ansari R, Bechar N, Koneru K, Govindan R, Wu J, Yu M, Schneider B, Hanna N (2010) Paclitaxel plus bevacizumab in patients with chemosensitive relapsed small cell lung cancer: a safety, feasibility, and efficacy study from the Hoosier Oncology Group. J Thorac Oncol 5(12): 2008-2011.

Jemal A, Bray F, Center MM, Ferlay J, Ward E, Forman D (2011) Global cancer statistics. CA Cancer J Clin 61(2): 69-90.

Johnson BE, Fischer T, Fischer B, Dunlop D, Rischin D, Silberman S, Kowalski MO, Sayles D, Dimitrijevic S, Fletcher C, Hornick J, Salgia R, Le Chevalier T (2003) Phase II study of imatinib in patients with small cell lung cancer. Clin Cancer Res 9(16 Part 1): 5880-5887.

Koinis F, Kotsakis A, Georgoulias V (2016) Small cell lung cancer (SCLC): no treatment advances in recent years. Transl Lung Cancer Res 5(1): 39-50.

Krug LM, Crapanzano JP, Azzoli CG, Miller VA, Rizvi N, Gomez J, Kris MG, Pizzo B, Tyson L, Dunne M, Heelan RT (2005) Imatinib mesylate lacks activity in small cell lung carcinoma expressing c-kit protein: a phase II clinical trial. Cancer 103(10): 2128-2131.

Kumar R, Knick VB, Rudolph SK, Johnson JH, Crosby RM, Crouthamel MC, Hopper TM, Miller CG, Harrington LE, Onori JA, Mullin RJ, Gilmer TM, Truesdale AT, Epperly AH, Boloor A, Stafford JA, Luttrell DK, Cheung M (2007) Pharmacokinetic-pharmacodynamic correlation from mouse to human with pazopanib, a multikinase angiogenesis inhibitor with potent antitumor and antiangiogenic activity. Mol Cancer Ther 6(7): 2012-2021.

Lucchi M, Mussi A, Fontanini G, Faviana P, Ribechini A, Angeletti CA (2002) Small cell lung carcinoma (SCLC): the angiogenic phenomenon. Eur $J$ Cardiothorac Surg 21(6): 1105-1110.

Michaelis LC, Ratain MJ (2006) Measuring response in a post-RECIST world: from black and white to shades of grey. Nat Rev Cancer 6(5): 409-414.

Micke P, Basrai M, Faldum A, Bittinger F, Ronnstrand L, Blaukat A, Beeh KM, Oesch F, Fischer B, Buhl R, Hengstler JG (2003) Characterization of c-kit expression in small cell lung cancer: prognostic and therapeutic implications. Clin Cancer Res 9(1): 188-194.

Motzer RJ, Hutson TE, Cella D, Reeves J, Hawkins R, Guo J, Nathan P, Staehler M, de Souza P, Merchan JR, Boleti E, Fife K, Jin J, Jones R, Uemura H, De Giorgi U, Harmenberg U, Wang J, Sternberg CN, Deen K, McCann L, Hackshaw MD, Crescenzo R, Pandite LN, Choueiri TK (2013) Pazopanib versus sunitinib in metastatic renal-cell carcinoma. $N$ Engl J Med 369(8): 722-731.

Mountzios G, Emmanouilidis C, Vardakis N, Kontopodis E, Hatzidaki D, Popis E, Karachaliou N, Kotsakis A, Agelidou M, Georgoulias V (2012) Paclitaxel plus bevacizumab in patients with chemoresistant relapsed small cell lung cancer as salvage treatment: a phase II multicenter study of the Hellenic Oncology Research Group. Lung Cancer 77(1): 146-150.

National Cancer Institute (2015) Common Terminology Criteria for Adverse Events. U.S. Department of Health and Human Services, National Institues of Health: Bethesda, MD, USA. http://evs.nci.nih.gov/ftp1/ CTCAE/CTCAE_4.03_2010-06-14_QuickReference_5x7.pdf (last accessed 29 September 2015).

O’Brien ME, Ciuleanu TE, Tsekov H, Shparyk Y, Cucevia B, Juhasz G, Thatcher N, Ross GA, Dane GC, Crofts T (2006) Phase III trial comparing supportive care alone with supportive care with oral topotecan in patients with relapsed small-cell lung cancer. J Clin Oncol 24(34): 5441-5447.

Owonikoko TK, Behera M, Chen Z, Bhimani C, Curran WJ, Khuri FR, Ramalingam SS (2012) A systematic analysis of efficacy of second-line chemotherapy in sensitive and refractory small-cell lung cancer. J Thorac Oncol 7(5): 866-872.

Pallis AG, Agelidou A, Agelaki S, Varthalitis I, Pavlakou G, Gerogianni A, Papakotoulas P, Rapti A, Chandrinos V, Christophyllakis C, Georgoulias V (2009) A multicenter randomized phase II study of the irinotecan/gemcitabine doublet versus irinotecan monotherapy in 
previously treated patients with extensive stage small-cell lung cancer. Lung Cancer 65(2): 187-191.

Ramalingam SS, Belani CP, Mack PC, Vokes EE, Longmate J, Govindan R, Koczywas M, Ivy SP, Gandara DR (2010) Phase II study of Cediranib (AZD 2171), an inhibitor of the vascular endothelial growth factor receptor, for second-line therapy of small cell lung cancer (National Cancer Institute \#7097). J Thorac Oncol 5(8): 1279-1284.

Ready NE, Pang HH, Gu L, Otterson GA, Thomas SP, Miller AA, Baggstrom M, Masters GA, Graziano SL, Crawford J, Bogart J, Vokes EE (2015) Chemotherapy with or without maintenance sunitinib for untreated extensive-stage small-cell lung cancer: a randomized, doubleblind, placebo-controlled phase ii study-CALGB 30504 (Alliance). J Clin Oncol 33(15): 1660-1665.

Rygaard K, Nakamura T, Spang-Thomsen M (1993) Expression of the proto-oncogenes c-met and c-kit and their ligands, hepatocyte growth factor/scatter factor and stem cell factor, in SCLC cell lines and xenografts. Br J Cancer 67(1): 37-46.

Salven P, Ruotsalainen T, Mattson K, Joensuu H (1998) High pre-treatment serum level of vascular endothelial growth factor (VEGF) is associated with poor outcome in small-cell lung cancer. Int J Cancer 79(2): 144-146.

Satouchi M, Kotani Y, Shibata T, Ando M, Nakagawa K, Yamamoto N, Ichinose Y, Ohe Y, Nishio M, Hida T, Takeda K, Kimura T, Minato K, Yokoyama A, Atagi S, Fukuda H, Tamura T, Saijo N (2014) Phase III study comparing amrubicin plus cisplatin with irinotecan plus cisplatin in the treatment of extensive-disease small-cell lung cancer: JCOG 0509. J Clin Oncol 32(12): 1262-1268.

Shinohara ET, Gonzalez A, Massion PP, Olson SJ, Albert JM, Shyr Y, Carbone DP, Johnson DH, Hallahan DE, Lu B (2007) PDGFR-beta expression in small cell lung cancer patients. Int J Radiat Oncol Biol Phys 67(2): 431-437.

Sternberg CN, Davis ID, Mardiak J, Szczylik C, Lee E, Wagstaff J, Barrios CH, Salman P, Gladkov OA, Kavina A, Zarba JJ, Chen M, McCann L, Pandite L, Roychowdhury DF, Hawkins RE (2010) Pazopanib in locally advanced or metastatic renal cell carcinoma: results of a randomized phase III trial. J Clin Oncol 28(6): 1061-1068.

Tas F, Duranyildiz D, Oguz H, Camlica H, Yasasever V, Topuz E (2006) Serum vascular endothelial growth factor (VEGF) and interleukin-8 (IL-8) levels in small cell lung cancer. Cancer Invest 24(5): 492-496.

Travis WD, Travis LB, Devesa SS (1995) Lung cancer. Cancer 75(1 Suppl): 191-202.

Ustuner Z, Saip P, Yasasever V, Vural B, Yazar A, Bal C, Ozturk B, Ozbek U, Topuz E (2008) Prognostic and predictive value of vascular endothelial growth factor and its soluble receptors, VEGFR-1 and VEGFR-2 levels in the sera of small cell lung cancer patients. Med Oncol 25(4): 394-399.

van der Graaf WT, Blay JY, Chawla SP, Kim DW, Bui-Nguyen B, Casali PG, Schoffski P, Aglietta M, Staddon AP, Beppu Y, Le Cesne A, Gelderblom H, Judson IR, Araki N, Ouali M, Marreaud S, Hodge R, Dewji MR, Coens C, Demetri GD, Fletcher CD, Dei Tos AP, Hohenberger P (2012) Pazopanib for metastatic soft-tissue sarcoma (PALETTE): a randomised, double-blind, placebo-controlled phase 3 trial. Lancet 379(9829): 1879-1886.

Van Glabbeke M, Verweij J, Judson I, Nielsen OS (2002) Progression-free rate as the principal end-point for phase II trials in soft-tissue sarcomas. Eur J Cancer 38(4): 543-549.

van Meerbeeck JP, Fennell DA, De Ruysscher DK (2011) Small-cell lung cancer. Lancet 378(9804): 1741-1755.

von Pawel J, Gatzemeier U, Pujol JL, Moreau L, Bildat S, Ranson M, Richardson G, Steppert C, Riviere A, Camlett I, Lane S, Ross G (2001) Phase ii comparator study of oral versus intravenous topotecan in patients with chemosensitive small-cell lung cancer. J Clin Oncol 19(6): 1743-1749.

von Pawel J, Jotte R, Spigel DR, O’Brien ME, Socinski MA, Mezger J, Steins M, Bosquee L, Bubis J, Nackaerts K, Trigo JM, Clingan P, Schutte W, Lorigan P, Reck M, Domine M, Shepherd FA, Li S, Renschler MF (2014) Randomized phase III trial of amrubicin versus topotecan as second-line treatment for patients with small-cell lung cancer. J Clin Oncol 32(35): 4012-4019.

von Pawel J, Schiller JH, Shepherd FA, Fields SZ, Kleisbauer JP, Chrysson NG, Stewart DJ, Clark PI, Palmer MC, Depierre A, Carmichael J, Krebs JB, Ross G, Lane SR, Gralla R (1999) Topotecan versus cyclophosphamide, doxorubicin, and vincristine for the treatment of recurrent small-cell lung cancer. J Clin Oncol 17(2): 658-667.

Zhan P, Wang J, Lv XJ, Wang Q, Qiu LX, Lin XQ, Yu LK, Song Y (2009) Prognostic value of vascular endothelial growth factor expression in patients with lung cancer: a systematic review with meta-analysis. J Thorac Oncol 4(9): 1094-1103.

This work is published under the standard license to publish agreement. After 12 months the work will become freely available and the license terms will switch to a Creative Commons AttributionNonCommercial-Share Alike 4.0 Unported License.

Supplementary Information accompanies this paper on British Journal of Cancer website (http://www.nature.com/bjc) 